CONF-961002--7

GA-A22474

CHARACTERIZATION OF
WALL CONDITIONS IN DIII-D

by

K.L. HOLTROP, G.L. JACKSON, A.G. KELLMAN, R.L. LEE,

W.P. WEST, R.D. WOOD, and D.G. WHYTE

PECEIVED

$A P R \quad 07997$

OSTI

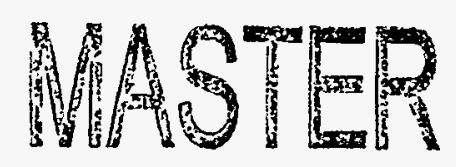

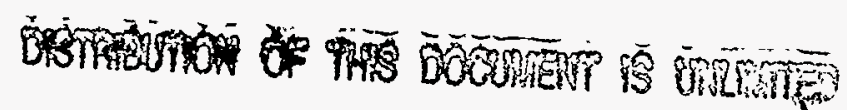

OCTOBER 1996 


\section{DISCLAIMER}

This report was prepared as an account of work sponsored by an agency of the United States Government. Neither the United States Government nor any agency thereof, nor any of their employees, makes any warranty, express or implied, or assumes any legal liability or responsibility for the accuracy, completeness, or usefulness of any information, apparatus, product, or process disclosed, or represents that its use would not infringe privately owned rights. Reference herein to any specific commercial product, process, or service by trade name, trademark, manufacturer, or otherwise, does not necessarily constitute or imply its endorsement, recommendation, or favoring by the United States Government or any agency thereof. The views and opinions of authors expressed herein do not necessarily state or reflect those of the United States Government or any agency thereof. 


\section{DISCLAMMER}

Portions of this document may be illegible in electronic image products. Images are produced from the best available original document. 


\title{
CHARACTERIZATION OF WALL CONDITIONS IN DIII-D
}

\author{
by \\ K.L. HOLTROP, G.L. JACKSON, A.G. KELLMAN, R.L. LEE, \\ W.P. WEST, R.D. WOOD, $†$ and D.G. WHYTE
}

This is a preprint of a paper to be presented at the 43rd Symposium and Topical Conference of the American Vacuum Society, October 14-18, 1996, in Philadelphia, Pennsylvania and to be published in the Journal of Vacuum Science and Technology.

\author{
$\dagger_{\text {Lawrence Livermore National Laboratory }}$ \\ 抽RS-Energie et Materiaux
}

\section{Work supported by the U.S. Department of Energy \\ under Contract NoS. DE-AC03-89ER51114 and W-7405-ENG-48}

GA PROJECT 3466

OCTOBER 1996 


\section{ABSTRACT}

Wall conditioning in DII-D is one of the most important factors in achieving reproducible high confinement discharges. For example, the very high confinement mode (VH-mode) was only discovered after boronization, a CVD technique to deposit a thin boron film over the entire surface of the tokamak. In order to evaluate wall conditions and provide a data base to correlate these wall conditions with tokamak discharge performance, a series of nominally identical reference $\mathrm{VH}$-mode discharges (1.6 MA, 2.1 T, double-null diverted) were taken at various times during a series of experimental campaigns with evolving wall conditions. These reference discharges have allowed a quantitative determination of how the wall conditions have evolved. For instance, core carbon and oxygen levels in the $\mathrm{VH}$-mode phase remained at historically low levels during the 1995 run year and there was also a steady decrease in the oxygen levels at plasma initiation during this period. We will discuss the long term changes in low $\mathrm{Z}$ impurities and the effect of wall conditioning techniques such as boronization and baking on these impurities. In addition, the evolution of the deuterium recycling rates will be discussed. 


\section{INTRODUCTION}

Steady progress in fusion research on the DIII-D tokamak [1] has been at least partially due to better first wall materials and improvements in wall conditioning techniques. However, the effects of wall conditioning are often long term and difficult to assess when implementing the complex DIII-D experimental program which incorporates plasmas with greatly different parameters. In order to assess wall conditions more quantitatively and provide input on whether conditions are sufficient to execute a specific experiment, a series of nominally identical reference discharges has been performed during the past five years. The effects of wall conditioning in DIII-D measured with these reference discharges is the subject of this paper.

The DIII-D tokamak has an Inconel vacuum vessel designed for ultrahigh vacuum, with a base pressure of $\mathrm{P}<2.0 \times 10^{-8}$ Torr. In operation since 1986 at General Atomics, it includes both $\mathrm{rf}$ and neutral beams for plasma heating and shaping, and has operated in a variety of different magnetic configurations and confinement regimes with near fusion reactor relevant parameters. The vessel itself is a toroidal shell with a D-shaped cross section. It has a volume of $35 \mathrm{~m}^{3}$, a major radius of $1.67 \mathrm{~m}$ and a minor radius of $0.67 \mathrm{~m}$. Plasma currents of up to $3 \mathrm{MA}$ with a toroidal magnetic field of $2.1 \mathrm{~T}$ are achievable. Except for port openings the DIII-D vessel is fully armored with graphite tiles (Union Carbide ATJ). The purpose for the graphite tiles is to reduce the metallic impurity influx into plasma discharges.

Careful conditioning of the DIII-D vessel, particularly the graphite tiles, must be performed in order to obtain high performance plasma discharges [2]. The principal methods for conditioning the graphite tiles for plasma discharge operation are baking, boronization, and $\mathrm{He}$ glow discharge cleaning [3]. These methods are discussed below.

The DIII-D vessel is routinely baked up to an average temperature of $350^{\circ} \mathrm{C}$. Baking reduces absorbed impurities such as water, oxygen (primarily as $\mathrm{CO}$ ) and nitrogen. In addition, baking 
lowers the bulk concentration of deuterium in the tiles allowing for better density control during a plasma discharge. Deuterium is released from the tiles as $\mathrm{D}_{2}$, hydrocarbons and as $\mathrm{D}_{2} \mathrm{O}$.

Boronization, first done on the TEXTOR tokamak [4], is a chemical vapor deposition (CVD) technique to deposit a thin boron film (approximately $100 \mathrm{~nm}$ ) over the entire surface of the tokamak. With the vessel at $250^{\circ} \mathrm{C}$ to $300^{\circ} \mathrm{C}$. a glow discharge is run, with a gas mixture of $20 \%$ diborane $\left(\mathrm{B}_{2} \mathrm{D}_{6}\right)$ and $80 \%$ helium, to deposit the boron film. Boronization reduces oxygen, coats metallic surfaces minimizing metallic impurity influx, and covers loose graphite resulting in lower levels of impurities in the plasma.

He glow discharge cleaning, performed before every plasma discharge, lowers the near surface concentration of deuterium and controls oxygen levels [3]. Typical glow sessions last 5 to 10 minutes with current densities of $7 \mu \mathrm{A} / \mathrm{cm}^{2}$ and average electrode voltages of $300 \mathrm{~V}$. 


\section{REFERENCE DISCHARGES}

Initially, reference discharges consisted of low power ohmically heated discharges similar to the programs on other tokamaks [5]. However except under conditions where the tokamak walls were very "dirty", e.g. due to a large air leak, there was little variation in the intrinsic impurities or performance of these discharges. High performance, auxiliary heated very high confinement (VH-mode) discharges were then chosen as the reference discharge set. These discharges have the advantage that they are very sensitive to wall conditions. For example VH-mode can only be achieved if the DIII-D first wall has a low oxygen and deuterium content and VH-mode was only discovered after the DIII-D tokamak was boronized [6]. Due to the importance of providing a well conditioned first wall, these reference discharges have been integrated into the DIII-D experimental program.

Parameters for these discharges are 1.6 MA, 2.1 T, double-null diverted VH-mode. A typical reference discharge is shown in Fig. 1. The target density at $1800 \mathrm{~ms}$ was approximately $2.8 \times 10^{19} \mathrm{~m}^{-3}$. A low target density is necessary in order to obtain $\mathrm{VH}-$ mode. A single neutral beam source $(2.5 \mathrm{MW})$ is turned on at $1000 \mathrm{~ms}$ and at $1800 \mathrm{~ms}$ the injected power is increased to approximately $8 \mathrm{MW}$. This additional power causes the plasma to transition from a regime of low energy confinement (L-mode) to a regime of high energy confinement ( $\mathrm{H}-$ mode) [7]. This transition, called the $\mathrm{L}-\mathrm{H}$ transition, occurs approximately $50-200 \mathrm{~ms}$ after the additional beam power at 1800 and can be seen as a drop in the $D_{\alpha}$ signal, which indicates the creation of a transport barrier which increases the particle confinment time and decreases the particle flow to the divertor.

After the plasma has entered the $\mathrm{H}$-mode phase, with the proper wall conditions there can be another transition into VH-mode. The transition to VH-mode is indicated by the increase in the energy confinement time, $\tau_{e}$, from the steady state level it had achieved in $\mathrm{H}$-mode (Fig. 1). For a VH-mode transition to occur the machine must be well-conditioned with low recycling, low 
density, low impurity levels, and low radiated power. Since the reference discharges were performed as part of the DIII-D experimental campaign, wall conditions allowed VH-mode to be reproducibly obtained. Reference discharges were not attempted when the machine was "dirty", such as during the vent recovery phase after a major machine opening.

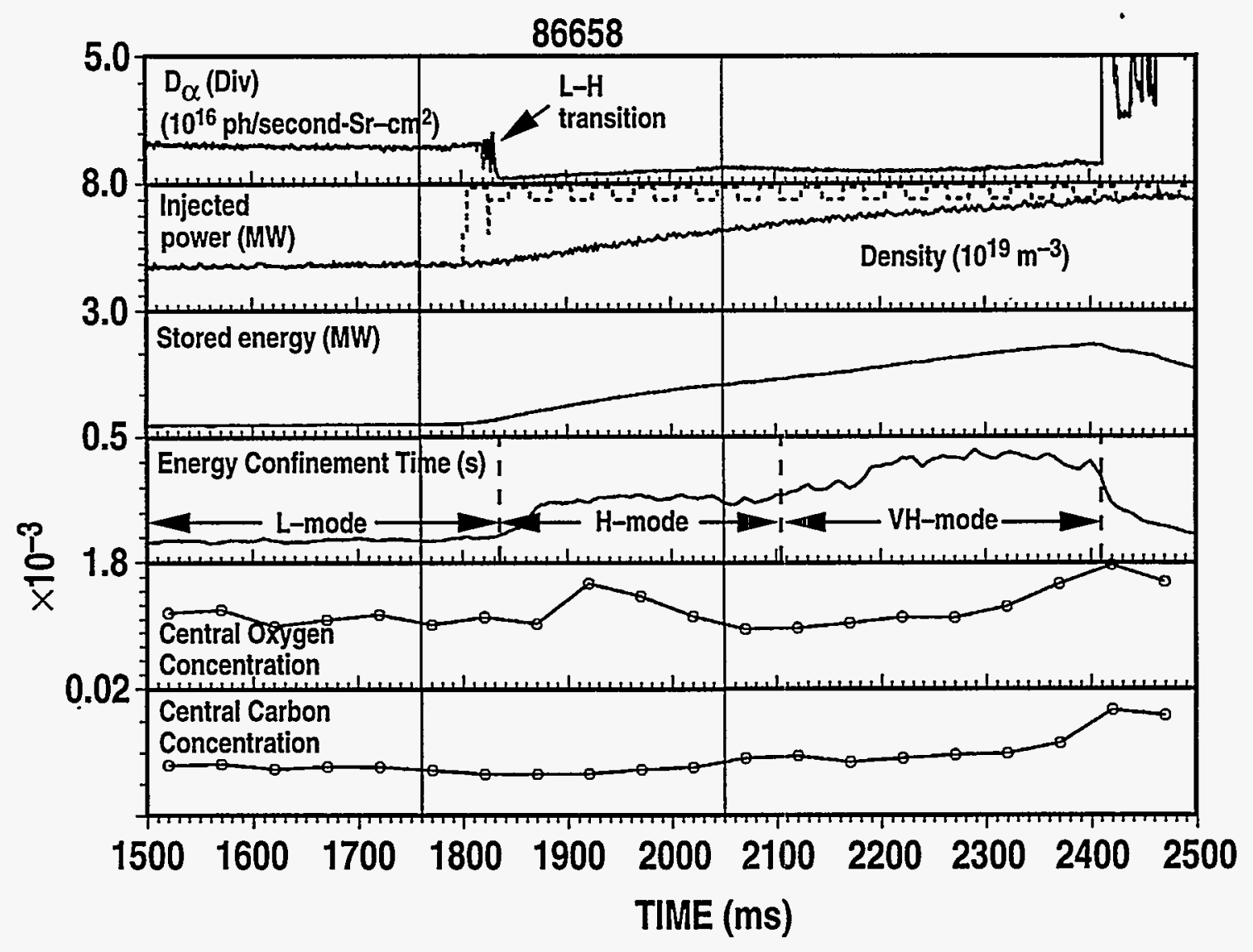

Fig. 1. Temporal evolution of a typical $\mathrm{VH}-$ mode reference discharge $\left(l_{p}=1.6 \mathrm{MA}, \mathrm{B}_{\mathrm{T}}=2.1 \mathrm{~T}\right)$. The analysis times at 1760 and $2050 \mathrm{~ms}$ are shown with solid lines. The $\mathrm{L}-\mathrm{H}$ transition (occurring at $1830 \mathrm{~ms}$ ) is quick and well defined. The $\mathrm{H}-\mathrm{VH}$ transition is also shown.

To quantitatively compare the reference discharges two analysis times were chosen. The first analysis time occurs at $1760 \mathrm{~ms}$ with the plasma in the L-mode phase. During the elm-free period following the $\mathrm{L}-\mathrm{H}$ transition (indicated by the low $\mathrm{D}_{\alpha}$ signal) the plasma parameters are continually evolving. The $\mathrm{L}-\mathrm{H}$ transition was used as a reference point with the second analysis time 200 ms later during the $\mathrm{H}$-mode phase since conditions during $\mathrm{H}$-mode can affect the VH-mode transition. The transition from L-mode to H-mode is very sharp and distinct. In 
contrast, the transition from $\mathrm{H}$-mode to $\mathrm{VH}$-mode is more gradual and it not always as well defined.

The reference discharges were obtained at various times during the experimental campaigns, including just prior to and just after a boronization. The reference discharge parameters were incorporated into a database which quantitatively tracked long term trends in 'vessel wall conditions and provided input on the proper time to boronize the vessel. A large variety of data was collected including information on impurities, radiated power, confinement times, neutron yield, and the mean ionic charge, $Z_{\text {eff }} \cdot Z_{\text {eff }}$ is defined as $\sum Z_{i}^{2} n_{i} / n_{e}$ where $Z_{i}$ is the atomic number of the $\mathrm{i}^{\text {th }}$ atom (usually $\mathrm{D}, \mathrm{He}, \mathrm{C}, \mathrm{O}$ and $\mathrm{N}$ in $\mathrm{DIII}-\mathrm{D}$ ). The following section will focus on the impurities due to the large effect they can have on plasma performance. 
. 


\section{IMPURITY LEVELS}

One of the most important factors in obtaining reproducible high performance plasma discharges is the control of impurities from the wall. If impurities enter the discharge they cause the plasma to lose energy through line radiation, loss of confinement, MHD instabilities and they increase the value of $Z_{\text {eff. }}$ Low $Z_{\text {eff }}$ values are important for several reasons. First, central impurity accumulation, i.e. high $\mathrm{Z}_{\mathrm{eff}}(0)$, dilutes the hydrogen central species on axis, which reduces the neutron rate, a key parameter in high performance discharges. Second, impurities can cause loss of confinement by termination of the high energy confinement phase, e.g. $\mathrm{H}$-mode or VH-mode. Finally, even small increases in low $\mathrm{Z}$ impurities, such as helium, can be detrimental when attempting high performance discharges in tokamaks [8].

The vessel, except for port openings, has been completely armored with graphite tiles since 1993. Due to this armoring there is little radiation loss from metallic impurities [9]. Instead the principal impurities are carbon, oxygen, helium and nitrogen. The concentrations of these impurities in the center of the discharge are determined from measured UV impurity charge exchange line intensities, calculated neutral beam penetration, and electron temperature and density profiles measured by Thomson scattering.

Carbon influxes are due to sputtering from the graphite walls. The sources of oxygen are from small air leaks on the vessel (the total air leak rate is approximately $2 \times 10^{-5}$ Torr- $\ell / \mathrm{s}$ ) and from water absorbed in the graphite tiles. The central oxygen and carbon levels from the plasma discharge during the $\mathrm{H}$-mode phase are plotted for the past several years in Fig. 2(a) and Fig. 2(b), respectively. Dashed lines indicate boronizations and solid diamonds indicate reference discharges taken within 30 discharges after a boronization. During 1992 the graphite coverage was only $40 \%$ of the vessel walls. Oxygen levels gradually declined in 1992 while carbon levels remained stable. At the beginning of 1993 the graphite tile coverage was increased to full 

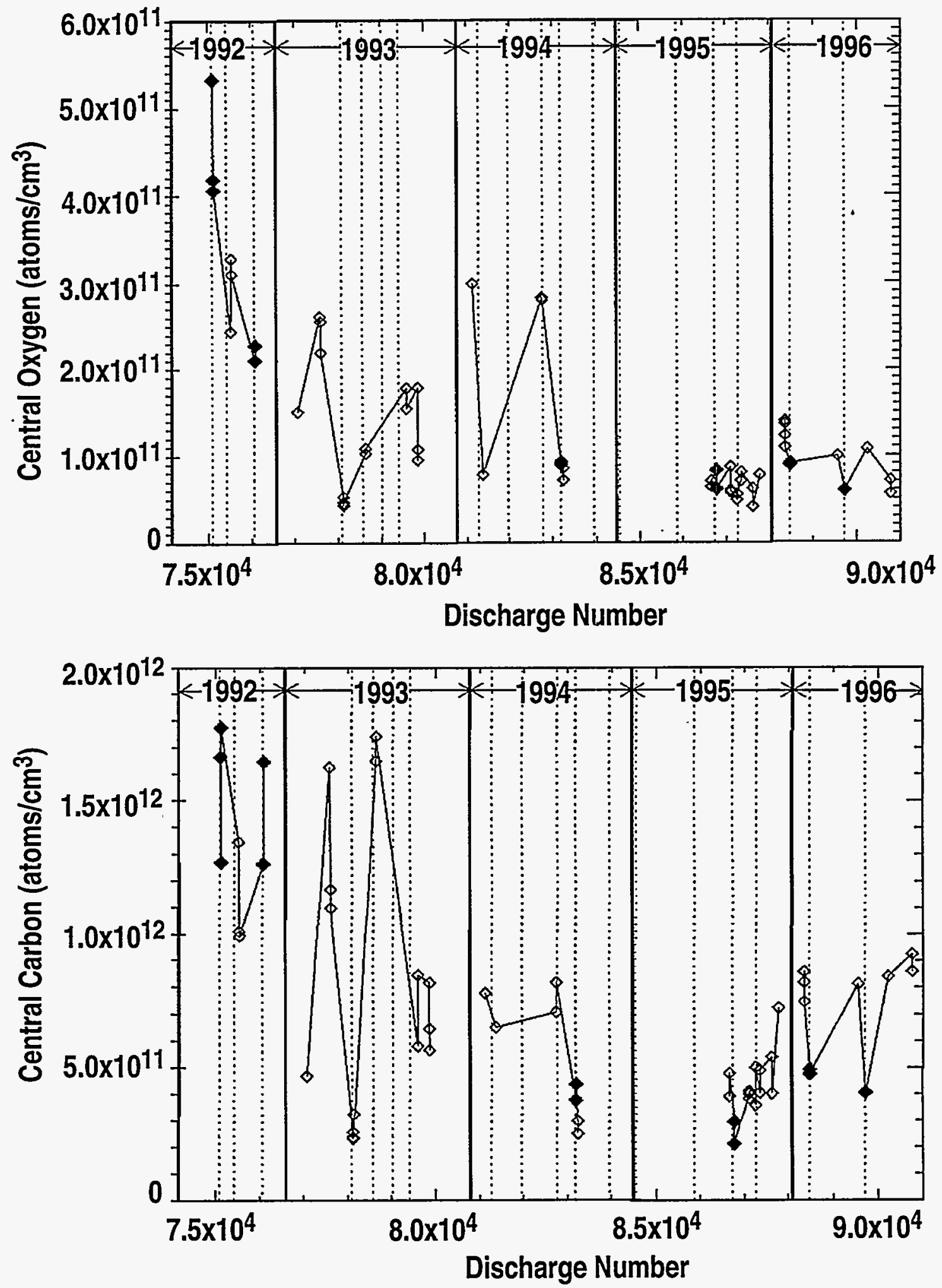

Fig. 2. (a) The central oxygen and (b) carbon concentration during the ELM free H-mode phase of the reference discharges shows a decrease from 1992 to 1995 . Dashed lines indicate boronizations and solid diamonds indicate discharges within 30 discharges of a boronization. 
coverage of the vessel. Careful attention was given to cleaning and outgassing the new tiles for installation in the DIII-D vessel [9]. In addition, the graphite tiles previously installed in the vessel were removed and all the impurities, including the boron film, on the tile surfaces were removed by grit-blasting [10]. Initial operation with the all graphite wall showed appreciably lower levels of both carbon and oxygen impurities. However, wall conditions degraded during the next several run weeks with both carbon and oxygen returning to 1992 levels. Due to the deteriorating wall conditions it was decided to boronize the vessel. Following this first boronization in 1993, with the new all-graphite wall, boron and oxygen levels fell to historically low levels. With continuing boronizations, this low level has been maintained until the present. However, there is a large variation in the carbon and oxygen levels for both 1993 and 1994. One reason for this could be due to a large asymmetry in the boron film deposition resulting in exposed graphite which could form a loose carbon layer. In addition, with the asymmetric film there could be a reduction in the passivation of surface oxygen. This asymmetry was caused by two factors both relating to the gas delivery system.

At the beginning of 1993 the diborane gas distribution system was upgraded. Prior to 1993 the gas for the boronization process was injected into the machine from two locations $180^{\circ}$ apart toroidally. From studies of surface samples placed around the vessel it was determined that the boron film was not being deposited uniformly. The boron film decayed away from the two injectors with an e-folding length of $0.9 \mathrm{~m}$ [11]. The 1993 upgrade consisted of splitting the two main feedlines into 16 stainless steel tubes routed around the vessel (with average runs of 20 feet) to various injection points. These injection points were spaced uniformly around the vessel to provide a distributed gas load and thus a more uniform boron film. During an inspection of the machine after the first boronization in 1993 it was discovered that three of these lines had ruptured. These lines were capped and not repaired until the end of 1993. In 1994 it was discovered that several of the boron tubes had become clogged. The vessel is heated during the boronization process and when the diborane flows through the thin tubes flakes of elemental boron form in the tubes. From the study of surface samples placed uniformly around the machine 
a large asymmetry in the boron film thickness was found that correlated with the location of the non-functioning tubes. An attempt was made to blow the tubes clean at the end of 1994 . A check of samples later in 1995 indicated that the boron film was much more uniform. The lines were blown clean again at the end of 1995 .

Throughout 1995, both carbon and oxygen remained at historically low levels. During the 1995 run year the carbon and oxygen levels did not decrease following boronizations. During the ELM free phase the carbon concentration was $0.5 \%-2.0 \%$, the oxygen concentration was $0.1 \%-$ $0.3 \%$, and the radiated power was $20 \%-50 \%$ of the total input power. Based on the constant low levels of carbon and oxygen it was decided to decrease the frequency of boronization from every three operational weeks to every six operational weeks. A typical run week has approximately 150 plasma discharges.

At the end of 1995 there was a month long air vent. This resulted in elevated carbon and oxygen levels at the beginning of 1996. After the first boronization, the levels return to 1995 levels. At the end of the first six week run period there was little increase in oxygen levels, however, there was a moderate increase in the carbon level. The carbon level dropped following the second boronization but rose again during the following run period. This increase in the carbon level is due to a large reduction in the thickness of the boron film deposited during the boronizations in 1996. A study of surface samples indicated that very little boron was being deposited in the vessel. The in-vessel lines were found to be heavily clogged with boron flakes. The working hypothesis is that blowing the lines clean does not remove all the flakes. As the boron flakes continued to form in the in-vessel tubes, they increased the surface area in the tubes, which accelerated the pyrolysis of the diborane. Eventually, the tubes became clogged to the point where very little diborane made it into the vessel.

Helium glow discharge was used between every discharge to lower the deuterium recycling level. Due to this there was always a small background level (1\%-3\%) of helium in the vessel (Fig. 3). However, just after a boronization there was a large increase in the helium level (solid diamonds indicate reference discharges within 30 discharges of a boronization). The feedgas for 
boronization consisted of a mixture of $20 \% \mathrm{~B}_{2} \mathrm{D}_{6}$ and $80 \%$ helium and even though a high temperature bake followed each boronization session not all the helium was removed from the tiles. Changes in $\mathrm{Z}_{\mathrm{eff}}$, due to increased helium influx, of up to 0.16 have been observed. Thus while oxygen and carbon influxes were generally reduced after boronization, the increase in helium offset some of the advantage, at least initially. The increase in helium was temporary and decayed away to normal background levels within 30 plasma discharges.

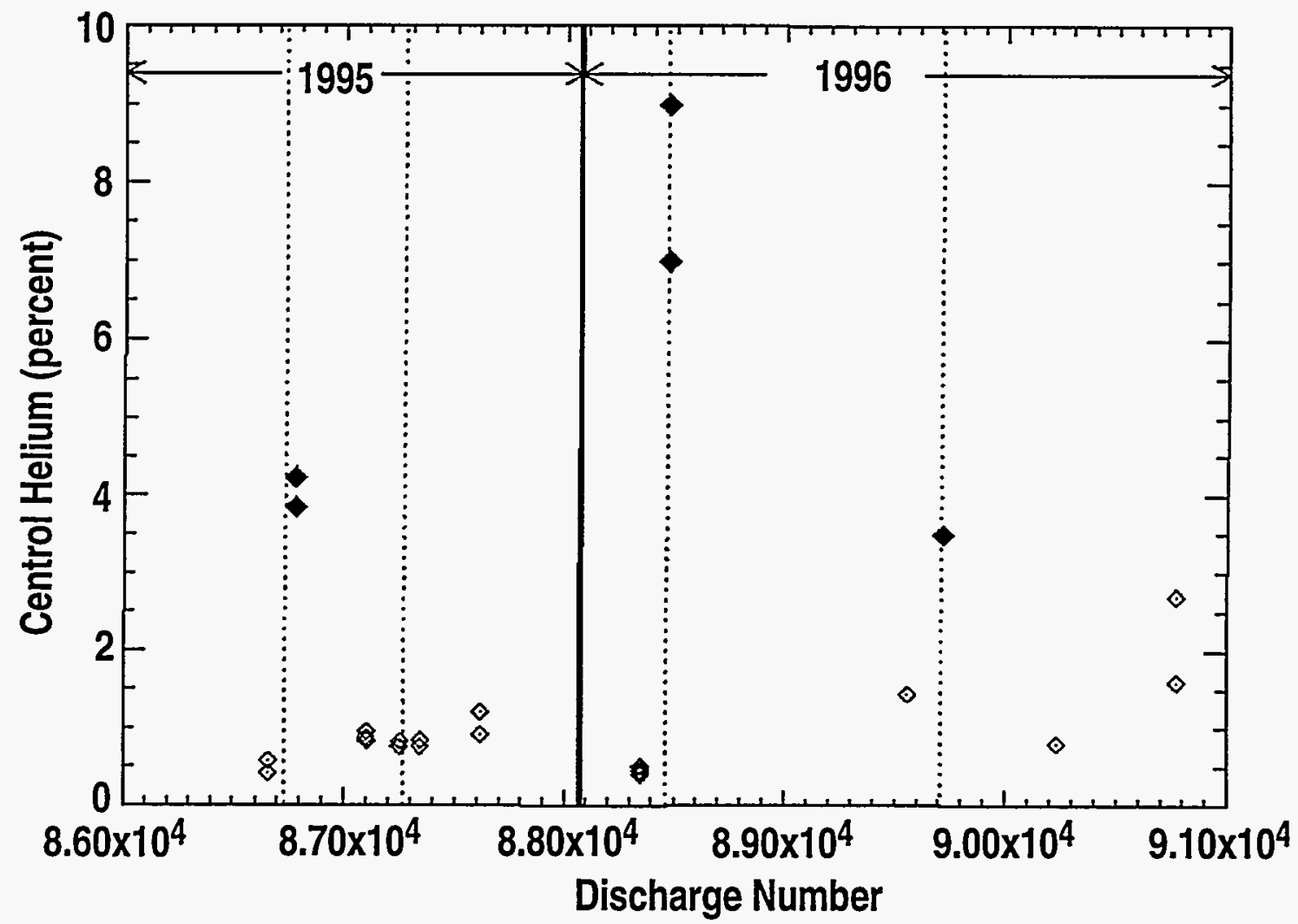

Fig. 3. The central helium level is stable during the 1995 and 1996 years. The two high values are for discharges directly following a boronization. This temporary increase in the helium level can increase $Z_{\text {eff }}$ by 0.16 .

The central nitrogen level remained at a low constant level during the 1995 and 1996 run year except for two sets of reference discharges (Fig. 4). The first set $(87774,87775)$ was after the vessel had been vented to dry $\mathrm{N}_{2}$ for repairs to a port. Following pump-down, the vessel was baked for 8 hours with the temperatures up to $330^{\circ} \mathrm{C}$. Despite the bake, the $\mathrm{N}_{2}$ level was approximately 20 times higher than normal. The second anomalously high value (90774) occurred just prior to the end of 1995 run year. This reference discharge was taken on the first 
day of plasma operations after the machine had been idle for approximately one month and the experiment on the last day of operations had puffed large amounts of $\mathrm{N}_{2}$ into the plasma. This $\mathrm{N}_{2}$ remained in the tiles during the month long maintenance period only being desorbed during plasma operations.

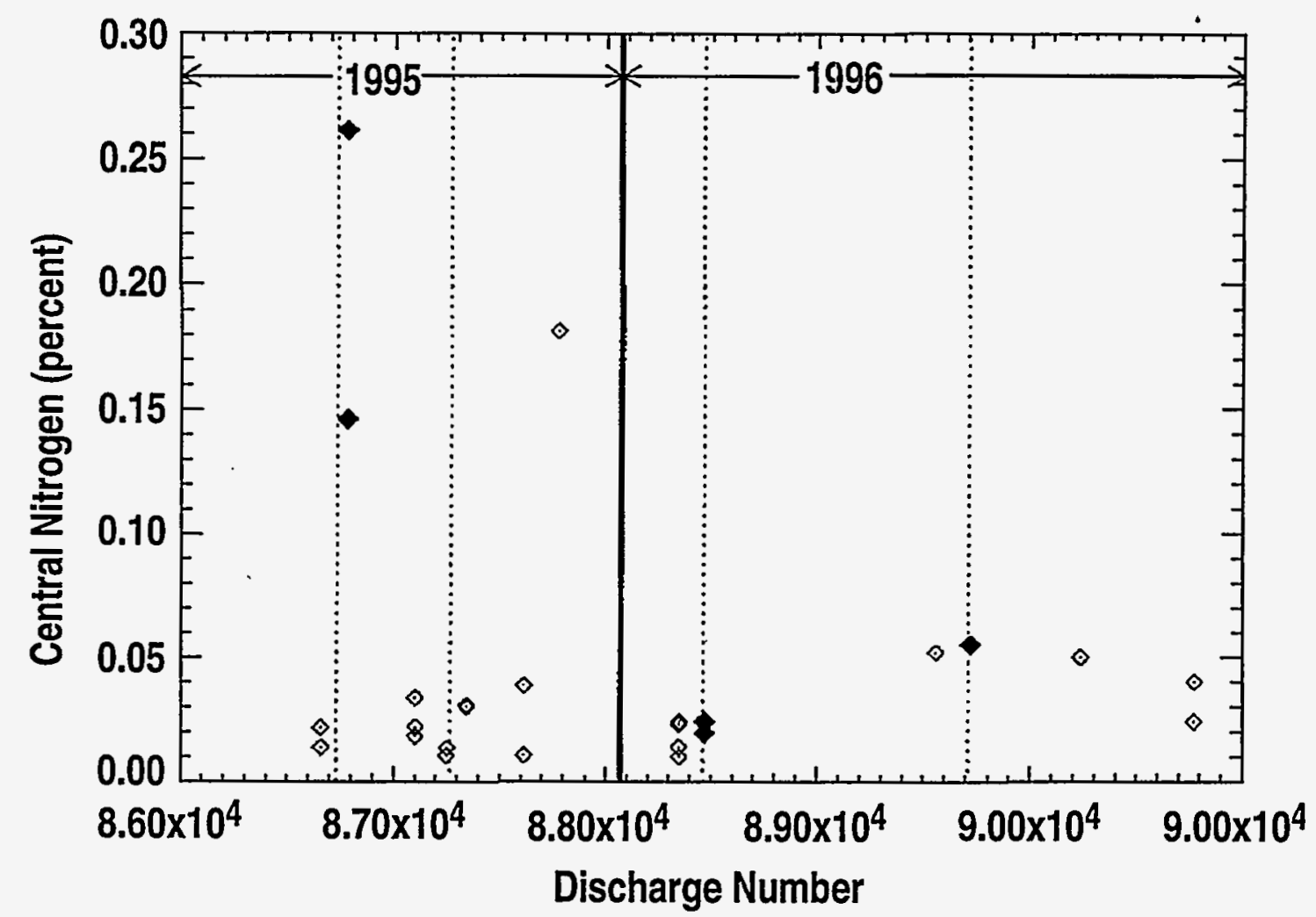

Fig. 4. The central nitrogen level remains stable throughout 1995 and 1996 except for two sets of discharges. The first set $(86777,86779)$ is caused by a dry $\mathrm{N}_{2}$ vent to air just prior to operations and the second (87774) with an experiment that ran just prior to the reference discharge where large amounts of $\mathrm{N}_{2}$ were puffed into the plasma.

The above discussion focused on the level of core plasma impurities during the $\mathrm{H}$-mode phase. Another indication of the cleanliness of the first wall is the oxygen line intensity, $\mathrm{O} \mathrm{V}$ $(629.7 \AA$ ), at the time of plasma initiation (Fig. 5). During 1995 this initial oxygen level declined during the entire year. After the prolonged air vent at the beginning of 1996 there was a large increase in the initial oxygen level. After the first boronization in 1996, the oxygen level decreased to a low level and remained there for the remainder of the year except for reference 
discharge 90236. The high level on discharge 90236 was due to a temporary air leak that had occurred just prior to the day's operations.

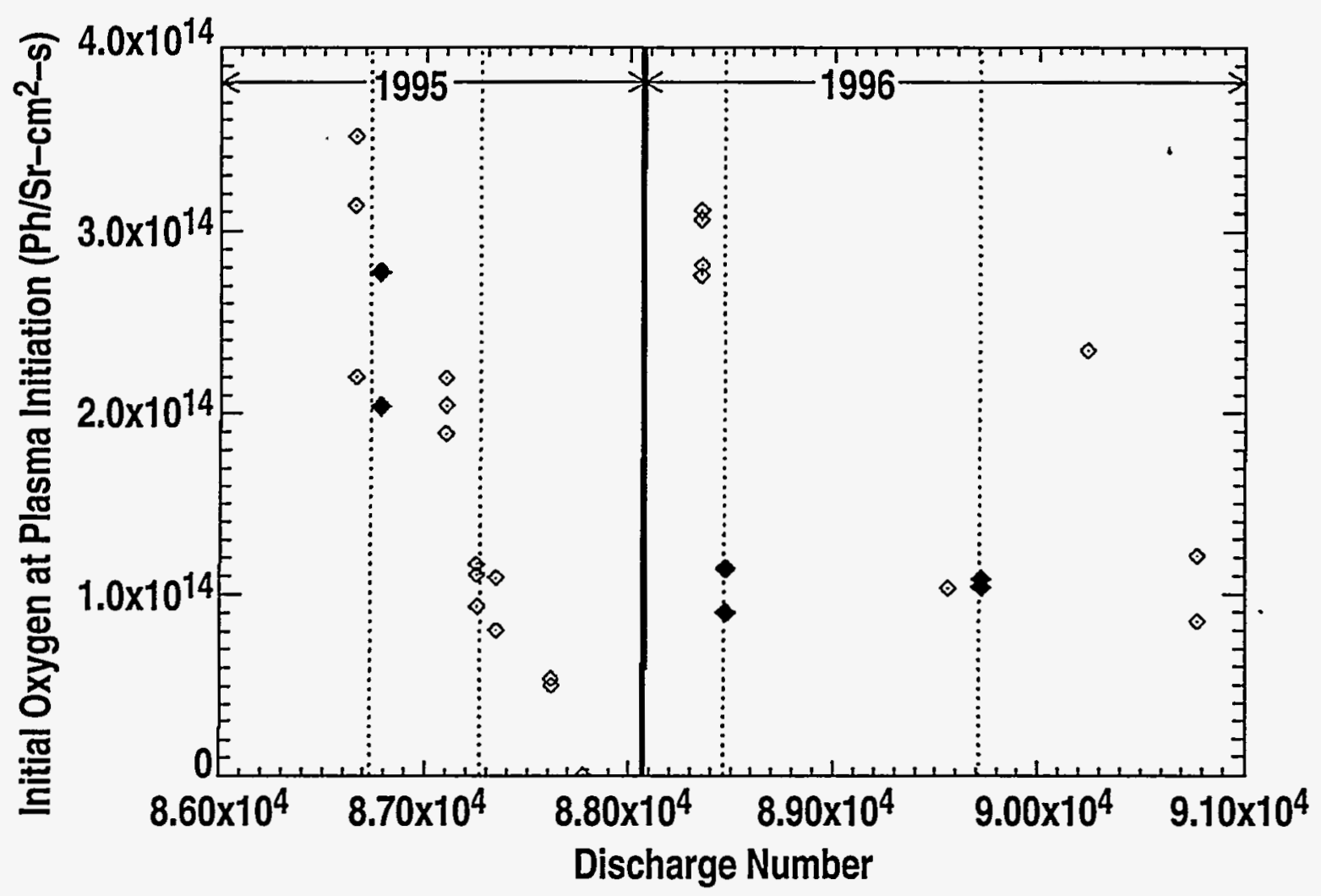

Fig. 5. The initial oxygen level for 1995 shows a continuous decline. There is an air vent at the beginning of 1996 causing the oxygen level to increase. Following the first boronization in 1996 the levels drop back down to the 1995 levels. They remain here for the remainder of the run period run period except for discharge 90236. On this shot there was a temporary air leak on the morning of plasma operations. 


\section{DEUTERIUM RECYCLING}

The recycling rate is an important factor in the density control of plasma discharges. When the graphite coverage of the vessel was increased from $9 \%$ to $40 \%$ (1988-1991) H-mode discharges could not be re-established until helium glow discharge cleaning was developed. Helium glow discharge reduces the recycling rate, allowing for better density control, which is a necessary prerequisite for obtaining $\mathrm{H}$-mode. In our present mode of operation a five to ten minute He glow discharge is run before every plasma discharge. When the glow time was shortened from 10 to 5 minutes for the reference discharges the wall recycling rate tended to increase. 



\section{CONCLUSION}

Reference VH-mode discharges were developed on the DIII-D machine. These discharges have allowed us to quantitatively track the central impurities in the machine. The reference discharge parameters were incorporated into a database which allows rapid determination on whether conditions are sufficient to execute a specific experiment. With the addition of the graphite wall and the upgraded boronization system the impurity levels have been reduced to historically low levels allowing for the operation of reproducible high performance discharges. Variations in the impurity levels during 1993 and 1994 appear to be due to non-uniform films caused by the rupture of the boronization gas feed lines and to their clogging with elemental boron flakes formed by the pyrolysis of diborane. When the boronization system was optimized during 1995 the impurities remained at historically low levels. For 1995, during the ELM free phase of the discharge, the central carbon concentration was $0.5 \%-2.0 \%$, the oxygen concentration was $0.1 \%-0.3 \%$, and the radiated power was $20 \%-50 \%$ of the total input power. For 1996 the oxygen level remained fairly constant but the carbon level showed moderate increases at the end of six week run period. This resulted from the reduced deposition of boron in the vessel. The working hypothesis is that the pyrolysis of diborane in the in-vessel tubes caused a steady accumulation of elemental boron flakes in the tubes, which increased the surface area available for pyrolysis to occur which further accelerated the process. During 1996, the tubes became clogged to the point where very little diborane made it into the vessel. 



\section{REFERENCES}

[1] V.S. Chan, Proceedings of the 16th IAEA Fusion Energy Conference, IAEA-CN-64-01-6.

[2] G.L. Jackson, T.S. Taylor, P.L. Taylor, Nucl. Fus. 30 (1990) 2305.

[3] G.L. Jackson, Journal of Vacuum Society and Technology A, 10 (1992) 1224.

[4] J. Winter, H.G. Esser, L. Könen, V. Phillips, H. Reimer, J.V. Seggern, J. Schülter, E. Vietzke, F. Waelbroeck, P. Wienhold, T. Banno, D. Ringer, S. Vep Y̌ek, J. of Nucl. Mater. 162-164 (1989) 713.

[5] P.H. La Marche, H.F. Dylla, M.G. Bell, F.P. Boody, C.E. Bush, R.J. Groebner, R.J. Hawryluk, K.W. Hill, D. Mueller, D.K. Owens, A.T. Ramsey, J.F. Schivell, S.S. Sesnic, M. Ulrickson, J. of Nucl. Mater. 145-147 (1987) 781.

[6] G.L. Jackson, et al., Phys. Rev. Lett. 67 (1991) 3098.

[7] R.J. Groebner, K.H. Burrell, R.P. Seraydarian, Phys. Rev. Lett 64 (1990) 3015.

[8] S.D. Scott, M.C. Zarnstorff, and the TFTR team, Bull. Am. Phys. Soc. 38 (1993) 2036.

[9] K.L. Holtrop, G.L. Jackson, A.G. Kellman, R.L. Lee, M.A. Hollerbach, J. Vac. Sci. Technol. A 12 (4), (1994). 
.[10] R.L. Lee, M.A. Hollerbach, K.L. Holtrop, A.G. Kellman, P.L. Taylor, W.P. West, Proc. 15th Symp. on Fusion Engineering, Hyannis, MA, (1993) 1181.

[11] G.L. Jackson, J. Winter, K.H. Burrell, J.C. DeBoo, C.M. Greenfield, R.J. Groebner, T. Hodapp, K.L. Holtrop, A.G. Kellman, R.L. Lee, S.I. Lippmann, R. Moyer, J. Phillips, T.S. Taylor, J. Watkins, W.P. West, J. of Nucl. Mater. 196-198 (1992) 236. 


\section{ACKNOWLEDGMENT}

Work supported by U.S. Department of Energy under Contract Nos. DE-AC03-89ER51114 and W-7405-ENG-48. 